\title{
International workshop on "Modeling interaction in biomolecules IV", held in Hrubá Skála, 14-19 September 2009
}

\author{
Jaroslav V. Burda • Andrzej W. Sokalski •
}

Jerzy Leszczynski

Published online: 17 September 2010

(C) Springer-Verlag 2010

The MIB IV conference was focused on modern computational techniques and advanced methods used to model systems and processes important in biophysics and biochemistry. The whole meeting consisted of several parts. Lectures delivered by invited speakers (R. Lindh, P. Politzer, A.M. Toro-Labbe, M.B. Hall, J. Vaniček, T. Clark, J. Luque, A. Michalak, J.S. Murray, D. Sundholm, T. Wesolowski, N. Gresh, S. Zaric, R. Ettrich, E. Broclawik, P. Cysewski and C. Lim) were designed to introduce particular topics, which were further elaborated in consequent talks of other speakers -including shorter contributions of junior researchers and Ph.D. students.

The opening lectures were delivered by W.A. Lester (University of California, Berkeley, CA, USA) and M. Olivucci (Università di Siena, Italy).
A poster student competition was organized during the poster sessions. Organizers are grateful to Springer publishing for donation to the three best poster projects (E. Chudyk, Wroclaw University of Technology, Poland; S. Taubert, University of Helsinki, Finland and L. Wolanski, Wroclaw University of Technology, Poland). The meeting was additionally supported by Schrödinger, LLC (http:// www.schrodinger.com) and Molecular Graphics and Modelling Society (http://www.mgms.org/).

The full program with titles of lectures and other details can be found on the web page: http://physics.mff.cuni.cz/ kchfo/MIB09.

At the conference, more than 100 researchers from 30 countries participated who delivered about 45 oral presentations and 50 posters.

\footnotetext{
J. V. Burda $(\square)$

Faculty of Mathematics and Physics, Charles University,

ke Karlovu 3,

12116 Prague, Czech Republic

e-mail: burda@karlov.mff.cuni.cz

\author{
A. W. Sokalski \\ Institute of Physical and Theoretical Chemistry, Wroclaw \\ University of Technology, \\ Wyb Wyspianskiego 27, \\ 50-370 Wroclaw, Poland \\ e-mail: sokalski@mml.ch.pwr.wroc.pl \\ J. Leszczynski \\ Computational Center for Molecular Structure and Interactions, \\ Jackson State University, \\ 1325 J. R. Lynch Street, \\ Jackson, MS 39217-0510, USA \\ e-mail: jerzy@icnanotox.org
}

